NBER WORKING PAPER SERIES

THE PRICING OF U.S. CATASTROPHE

REINSURANCE

Kenneth A. Froot

Paul G. J. O’Connell

Working Paper 6043

\author{
NATIONAL BUREAU OF ECONOMIC RESEARCH \\ 1050 Massachusetts Avenue \\ Cambridge, MA 02138 \\ May 1997
}

This paper was prepared for the NBER Conference on The Financing of Property/Casualty Risks, Palm Beach, FL, November 21-23, 1996. We are grateful to Peter Diamond, Chris Milton, Julio Rotemberg, Jeremy Stein, René Stulz and conference participants for helpful comments, to David Govrin, Chris McGhee, Denis Medvedsek, Brian Murphy, and Barney Schauble for help in obtaining and understanding reinsurance data, and to the NBER and Division of Research at Harvard Business School for generous research support. All errors are our own. This paper is part of NBER's research program in Corporate Finance. Any opinions expressed are those of the authors and not those of the National Bureau of Economic Research.

(C) 1997 by Kenneth A. Froot and Paul G. J. O'Connell. All rights reserved. Short sections of text, not to exceed two paragraphs, may be quoted without explicit permission provided that full credit, including $(\mathcal{C}$ notice, is given to the source. 
The Pricing of U.S. Catastrophe Reinsurance

Kenneth A. Froot and Paul G. J. O'Connell

NBER Working Paper No. 6043

May 1997

JEL No. 400

Corporate Finance

\begin{abstract}
We explore two theories that have been advanced to explain the patterns in U.S. catastrophe reinsurance pricing. The first is that price variation is tied to demand shocks, driven in effect by changes in actuarially expected losses. The second holds that the supply of capital to the reinsurance industry is less than perfectly elastic, with the consequence that prices are bid up whenever existing funds are depleted by catastrophe losses. Using detailed reinsurance contract data from Guy Carpenter \& Co. over a 25-year period, we test these two theories. Our results suggest that capital market imperfections are more important than shifts in actuarial valuation for understanding catastrophe reinsurance pricing. Supply, rather than demand, shifts seem to explain most features of the market in the aftermath of a loss.
\end{abstract}

Kenneth A. Froot

Graduate School of Business

Harvard University

Soldiers Field Road

Boston, MA 02163

and NBER

kfroot@hbs.edu
Paul G. J. O'Connell

Department of Economics

Harvard University

Cambridge, MA 02138

poconnel@husc3.harvard.edu 


\section{The Pricing of U.S. Catastrophe Reinsurance}

\section{Introduction}

The price of catastrophe reinsurance in the U.S. has fluctuated markedly in recent years. These fluctuations are commonly associated with the pattern of catastrophe occurrences. For example, catastrophe losses during the 1992-1994 period totaled $\$ 38.6$ billion in 1994 dollars, exceeding the cumulative total of losses during 1949-1991 of $\$ 34.6$ billion. During this three-year period, prices on catastrophe reinsurance cover more than doubled, and then began to decline thereafter. What drives such changes in price? Does the demand for reinsurance shift, does the supply of reinsurance capital change, or do both occur? ${ }^{1}$

If catastrophe losses lead to a decrease (leftward shift) in supply, then we would expect to see increases in price coupled with declines in quantity after an event. Of course, a decline in supply is possible only in the presence of some form of capital market imperfection. If capital markets were perfect, the supply curve for reinsurance would be perfectly elastic. In this case, regardless of losses, the price of reinsurance would be fixed, where the "price" of a contract is best thought of as the ratio of premiums to actuarially expected losses covered under that contract. Capital market imperfections would imply that the marginal cost of producing reinsurance is increasing in the quantity supplied. Thus, these imperfections lead to an upward sloping supply curve, which (all else equal) can shift back as a result of reinsurer losses. Such a supply shift increases price and reduces quantity. As with price, it is best to think of this "quantity" as the actuarially expected loss covered by reinsurance.

On the other hand, catastrophe losses may lead to increases in demand. Rightward demand shifts can be thought of as the result of an actual or perceived increase in actuarial losses covered by a given contract. We call this "probability updating." Naturally it would seem possible to identify such demand shifts from the fact that they lead to an increase in price and quantity. Thus, conditional on a loss, an

\footnotetext{
' A number of papers have investigated these cycles, attempting to identify supply versus demand shocks in insurance markets. Cummins and Outreville (1987) show that lags in data collection or price regulation can generate cycles in property-casualty underwriting margins. Gron (1994) presents evidence that, assuming there are no marketwide demand shocks, the cycles in property-casualty margins are due to variation in the supply of insurance capacity, rather than institutional lags or reporting practices. Gron and Lucas (1995) investigate why these cycles appear to be so persistent. They find that when the net worth of insurers declines, the total amount of capital raised through security issues is small. See also Winter (1988) and Cummins and Danzon (1991).
} 
absolute decline in the quantity of reinsurance purchased would be evidence of important leftward shifts in supply, even if there were also positive increases in demand.

We look for such absolute declines in quantity, but in addition, we pursue the probability updating hypothesis further. While it is impossible to distinguish between probability updating and capital market imperfections based on the behavior of aggregate price indexes over time, it is possible to distinguish between them based on the behavior of cross-sectional changes in reinsurance prices. Specifically, probability updating ought to vary across contracts, with larger price increases associated with contracts for which more probability updating occurs. We therefore examine cross-sectional price increases in response to an event, and determine the extent to which they are explained by relative contract exposures.

To see how this works, consider a catastrophe loss caused by a winter freeze in New England. We might expect such a loss to affect strongly (and positively) the distribution of prospective losses due to freeze and/or the distribution of prospective losses from other perils in New England. After all, the event may cause people to recognize how much damage a freeze can do, or to learn about the replacement costs of certain physical assets in New England. However, such updates in knowledge would have little or no import for the distribution of catastrophe losses outside of New England where freezes do not occur. Specifically, little would be learned about loss exposures in California (which faces primarily earthquake risk), the Southeast (which faces primarily hurricane risk), or Texas (which faces primarily windstorm risk). Under probability updating, it follows that contracts with relatively little exposure to freeze and/or to the Northeast region ought to have relatively small price increases. In this way, we are able to further distinguish between capital market imperfections and probability updating.

Our identification strategy is made possible through the use of a unique and detailed data set from Guy Carpenter \& Co., by far the largest catastrophe reinsurance broker for U.S. catastrophe exposures. These data include all U.S. catastrophe reinsurance contracts brokered by Guy Carpenter between 1970 and 1994. They allow us to measure prices and contract losses, and to go about the complex process of estimating each contract's exposure to different event types and regions.

To preview our results, we find that supply, rather than demand, shocks are more important for understanding the effect of losses on reinsurance prices and quantities. Capital market imperfections therefore appear to be the dominant explanation. There is limited evidence for probability updating, and what evidence there is suggests that the effect is of a small magnitude. The magnitudes of the supply effects are large: after controlling for relative contract exposure, a $\$ 10$ billion catastrophe loss raises 
average contract prices by between $19 \%$ and $40 \%$, and reduces quantity of reinsurance purchased by betwee11 $5 \%$ and $16 \%$.

The rest of the paper is organized as follows. Section 2 sets out our identification strategy and the structure of our empirical tests. Section 3 describes our data sources. In Section 4 , the calculation of contract exposure and price is discussed in detail. We devote considerable attention to the calculation of exposure, which requires a number of involved steps. Section 5 provides a brief graphical analysis. The empirical testing is carried out in Section 6. Section 7 summarizes and offers our conclusions.

\section{The price and quantity of reinsurance}

We examine the equilibrium prices and quantities of single-event, excess-of-loss reinsurance contracts. These contracts help reinsure insurance companies against losses resulting from natural catastrophes in the US, such as windstorm or earthquake.

To understand how such contracts work, consider an insurer which purchases a layer of reinsurance covering $\$ 100$ million losses in excess of $\$ 200$ million. These terms imply that if the insurer's losses from a single catastrophic event during the contract year exceed $\$ 200$ million (the "retention"), the layer is triggered. The reinsurer pays the insurer the amount of any losses in excess of $\$ 200$ million, with the maximum payment - the "limit"-capped at $\$ 100$ million. ${ }^{2}$ By purchasing this contract, the insurer cedes its exposure to single-event catastrophe losses in the $\$ 200-\$ 300$ million range. In return for assuming this exposure, the reinsurer receives a payment, known as the "premium." If the insurer wishes to cede a broader band of exposure, it could purchase additional layers- $-\$ 100$ million in excess of $\$ 300$ million, $\$ 100$ million in excess of $\$ 400$ million, and so on.

The price of a reinsurance contract is best measured as the premium per unit of exposure. In the marketplace, premium is usually expressed relative to limit (the ratio is called "rate-on-line"). However, limit is a poor proxy for contract exposure-it ignores the level of the contract's retention, for example. To remedy this, we measure price by premium per unit of actuarially expected loss. Indeed, we use actuarially expected loss as our measure of the "quantity" of reinsurance purchased.

In Section 4, we describe how historical data on catastrophe losses and company specific market share information can be used to measure the actual exposure of each reinsurance contract. It is important to emphasize that we measure actuarially expected loss from a loss distribution that is time-

\footnotetext{
${ }^{2}$ To guard against moral hazard, excess-of-loss reinsurance contract typically require coinsurance. In practice, this effectively means that the insurer provides $5-10 \%$ of the reinsurance.
} 
invariant. We cannot condition our measures of expected loss on previous losses. To the extent that loss distributions shift in response to recent loss history, we measure both quantity and price with error. These potential mismeasurements are important for the way we specify our tests and hypotheses.

\subsection{Identifying capital market imperfections}

As noted in the introduction, we investigate two channels by which catastrophe losses affect reinsurance prices and quantities. First, "capital market imperfections" may impede the flow of capital into the reinsurance sector. There may be several sources of such imperfections. One is that existing reinsurers may find it costly or undesirable to raise additional external capital. These costs could result from information asymmetries between managers and owners (which implies equity-sale announcements drive down share prices) or from dilution of managerial control (which implies managers are averse to expanding the capital base). Another potential source of imperfection is that it is costly to carry equity capital. These costs may accrue from foregone tax shields, agency problems, or, in the case of reinsurers, frictional collateral costs. ${ }^{3}$

If we could accurately measure, at each point in time, the distribution of one-year-ahead losses conditional on all information, then it would be relatively simple to test the capital-market imperfections story. In the presence of such imperfections, capital depletion associated with event losses constricts the supply of reinsurance, driving up the price of all contracts. If, for example, the event were a hurricane, the supply of hurricane reinsurance capacity would fall. So would the supply of non-hurricane reinsurance capacity, since both exposures are borne by the same capital base. Figure 1 below shows the impact on equilibrium prices and quantities for contracts that are exposed to hurricane risk-Panel (a)and those that are not-Panel (b). Note that the exposure supply curves are upward sloping. This is due to the capital market imperfections, which raise the marginal cost at which reinsurers are able to offer successively greater exposure protection to insurers. ${ }^{4}$

\footnotetext{
${ }^{3}$ See Froot (1996) for a survey of these costs and their impact on financing patterns. Froot and Stein (1997) study the implications for financial intermediaries of costly equity finance.

${ }^{4}$ See Froot and Stein for a model of the reservation price a financial intermediary such as a reinsurer is willing to offer marginal units of risk exposure.
} 


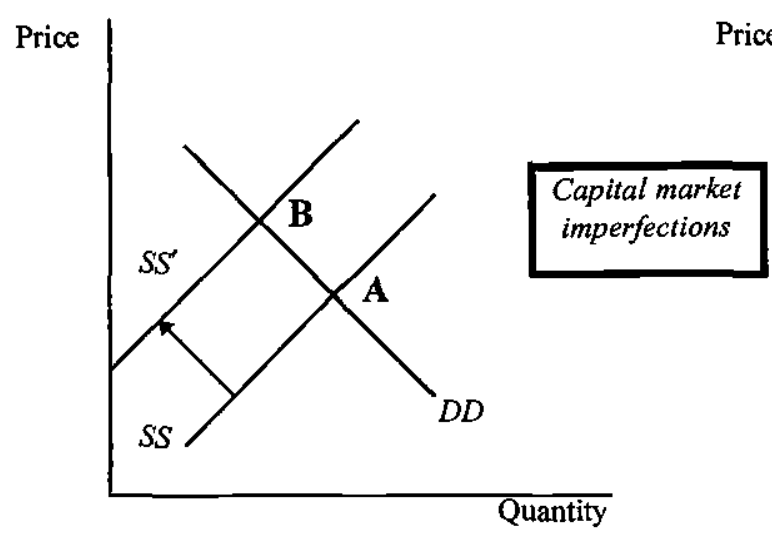

(a) Hurricane-exposed contracts

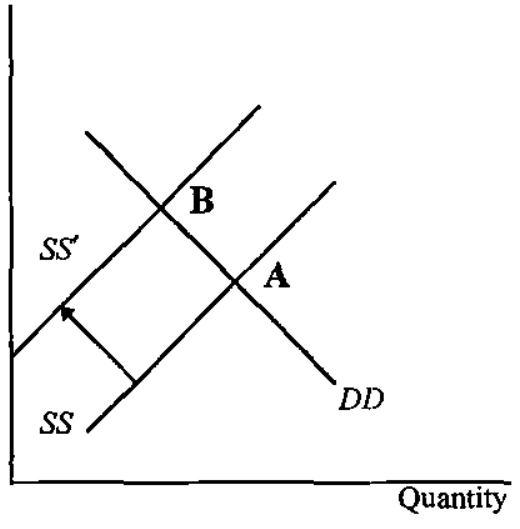

(b) Non-hurricane-exposed contracts

Figure 1: Capital market imperfections

Figure l suggests that capital market imperfections generate a negative correlation between prices and quantities, since loss shocks lead to shifts in the supply curve. If losses lead to demand curve shifts, on the other hand, a positive correlation between price and quantity results.

Since negative correlation would seem to be evidence in favor of supply shifts (and, therefore, capital-market imperfections), it seems useful to ask whether prices and quantities are in fact negatively correlated. Figure 4 and Figure 5 show our measures of quantity and price, respectively, for the sample period for which we have contract data. ${ }^{5}$ More specifically, Figure 4 shows an index of the total quantity of catastrophe exposure that was ceded in the U.S. reinsurance market from 1975:1-1993:4. The series is calculated by summing all the exposure embodied in the excess-of-loss contracts in each quarter, and dividing it by the total market share represented by the contracts. Figure 5 plots the industry price series quarterly from 1975:1-1993:4. Each observation is the exposure-weighted average of the price of all contracts that are in force in that quarter. ${ }^{6}$

A number of features of these figures are noteworthy. First, it appears that quantities rose and prices fell for much of the late 1970s and 1980s. Second, a startling rise in prices and decline in quantities took place beginning in the mid-1980s through the end of the sample. Indeed, in 1993, price was between 5 and 7 times its historical average. This will come as no surprise to industry observers. It is common to relate this price rise to the occurrence of a number of large events during this period, notably hurricane Andrew ( $\$ 20$ billion in losses) in August 1992, hurricane Hugo in 1989 and several windstorms in 19851986. Figure 6, which plots total catastrophe losses by quarter from 1970:1-1994:4 as measured by

\footnotetext{
${ }^{5}$ For a description of our data and the computation of prices and quantities, see Section 3.
} 
Property Claims Services, lends support to this view. In the period since 1994 (for which we have no data), the price of reinsurance has declined and quantity increased somewhat, notwithstanding the occurrence of the Northridge earthquake in January 1994. From these observations, it is clear that there is considerable negative correlation between prices and quantities at frequencies of several years.

Figure 7 and Figure 8 provide further evidence of the apparent negative correlation between equilibrium prices and quantities. Figure 7 plots industry price-quantity pairs. It is interesting because it suggests the existence of two regimes in catastrophe reinsurance pricing. The 1970s and early 1980s saw strong expansion in the quantity of risk ceded coupled with a moderate decline in per-unit prices. The late 1980 s and early 1990 s were characterized by ballooning prices coupled with quantity declines. One interpretation of these patterns is that the 1970 s and 1980 s were a period of expanding reinsurance demand, while the 1990s exhibit a contraction of reinsurance supply. Figure 8 plots each contract's price against its exposure. Both variables have been demeaned by insurer. As indicated by the linear fit to the plot (slope -0.32 , standard error 0.04), when a contract embodies less-than-average exposure, it tends to be priced above average. Taken at face value, the points appear to lie on firm-specific reinsurance demand schedules. Or put another way, strong evidence of negative correlation between price and quantity, suggests that shifts in the reinsurance supply curve have been important.

Taken by itself, this evidence would seem to support the hypothesis of capital market imperfections. However, it is important to see the implications of demand shocks, or what we call "probability updating." Probability updating holds that the occurrence of a catastrophe may raise the real or perceived distribution of losses above what we measure with our time-invariant loss distribution. For example, after Hurricane Andrew in 1992, some insurers were surprised that the construction methods used for houses in Homestead, FL performed so poorly in high winds. Andrew might have also led to upward shifts in agents' subjective distributions.

To see the effects of probability updating, suppose that after a particular event, say, a hurricane, agents update positively about the likelihood of hurricane losses. Then even if the premium per unit of actual exposure stays constant, the ratio of premium to observed exposure rises. This is because we measure exposure from a time-invariant loss distribution. Figure 2 traces this effect on supply and demand. Suppose that capital markets are perfect-the supply of capital to the reinsurance sector is infinitely elastic at a given price. In the aftermath of the hurricane, the observed supply curve shifts up as

\footnotetext{
${ }^{6}$ These industry series are based on the contract prices and exposures for four insurers that purchased reinsurance through Guy Carpenter \& Co. in every year from 1975 to 1993 . The series are representative of the behavior of prices and quantities for the other insurers in our database.

${ }^{7}$ See Section 3 for a description of this loss series.
} 
shown in Panel (a). To understand what happens to the demand schedule, consider an insurer which, at a given price, wants to cede the same amount of exposure before and after the hurricane. Since the perceived risk of hurricanes increases, the terms of this insurer's contract must be rewritten to keep exposure constant. For example, the retention on the contract could be raised. Any such change that keeps actual ceded exposure constant causes measured exposure to fall and concomitantly measured price to rise. Thus the entire observed demand schedule shifts upwards and to the left. All of this assumes that there is no actual change in demand. However, the demand curve may exhibit further changes as agents alter the amount of reinsurance they are willing to demand at a given price. For example, the demand schedule may shift out if homeowners learn from the hurricane that they are underinsured. Alternatively, the schedule may shift in if coastal homeowners who sustain severe damage from the hurricane elect to move to a less-exposed inland region rather than to rebuild in situ.

Consequently the overall effect on the observed demand curve is ambiguous. If the observed $D D$ curve experiences no net shift at all, the equilibrium moves from point $\mathbf{A}$ to $\mathbf{C}$, which results in an increase in price and a decrease in demand. Thus, demand shifts combined with probability updating can duplicate the finding that prices increase while quantities decrease. We therefore cannot conclude that such negative correlation is evidence of capital market imperfections. On the other hand if the observed $D D$ curve shifts out on net, as shown in the figure, the equilibrium shifts from point $\mathbf{A}$ to $\mathbf{B}$.

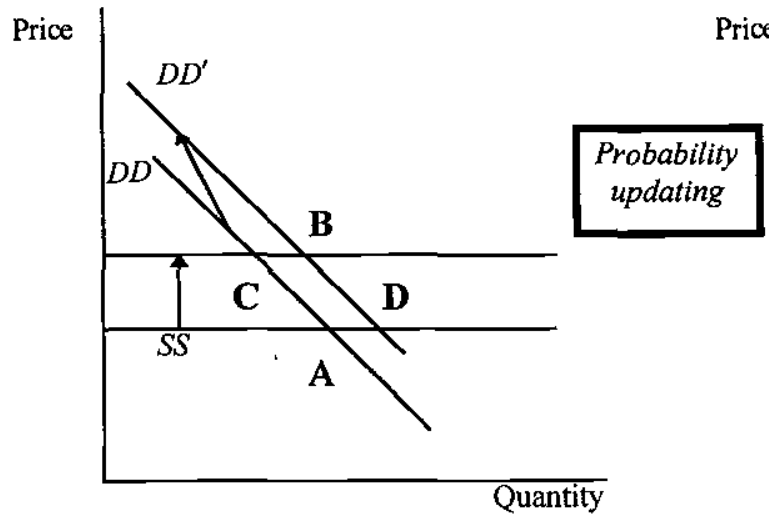

(a) Hurricane-exposed contracts

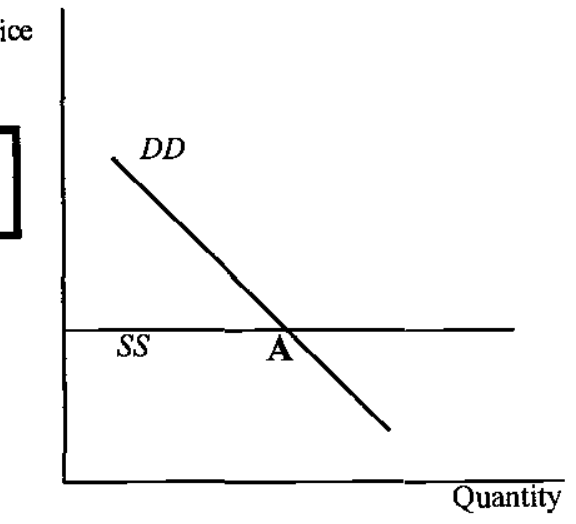

(b) Non-hurricane-exposed contracts

Figure 2: Probability updating

Probability updating, then, complicates the process of identifying capital market effects. To overcome this problem, consider the following identification strategy. Assume that hurricane losses may lead to probability updating for hurricanes, but not for other types of events in other regions. The idea 
here is simple: if a hurricane occurs, it may not alter the perceived frequency or severity of non-hurricane events. Accordingly, probability updating from a hurricane should produce no change in prices or quantities for contracts that have little or no hurricane exposure. However, if there are capital market imperfections, then prices tend to increase and quantities decrease on non-hurricane exposed contracts.

Figure 3 illustrates. A hurricane loss that raises the perceived likelihood of future hurricane loses will simultaneously shift the observed demand and supply curves upwards and to the left.. These effects are shown as movements in the schedules from $D D$ to $D D^{\prime}$ and $S S$ to $S S^{\prime \prime}$ in Panel (a), which together produce an increase in price. There are no such probability-updating effects for the contracts that are not exposed to hurricane risk in Panel (b). However, if the catastrophe loss depletes the pool of capital that is available to the industry for all types of reinsurance, then the supply schedule for both types of contracts shifts back to $S S^{\prime \prime}$. In these circumstances we can expect the price of both to increase.

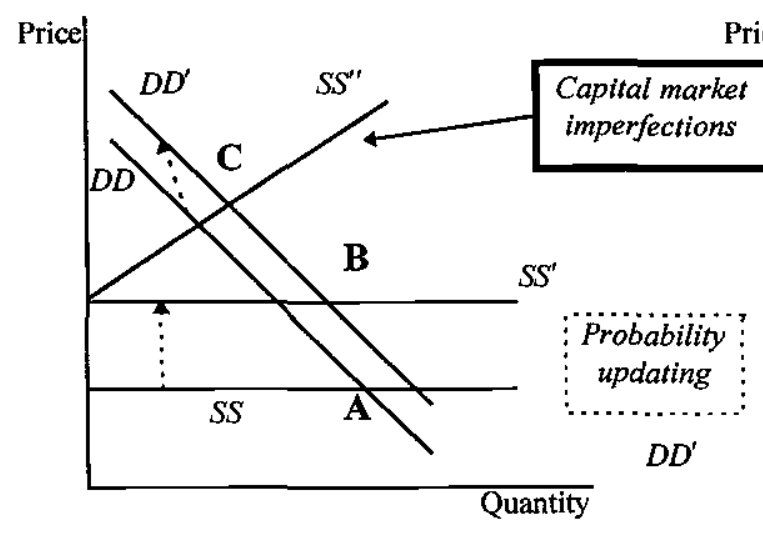

(a) Hurricane-exposed contracts

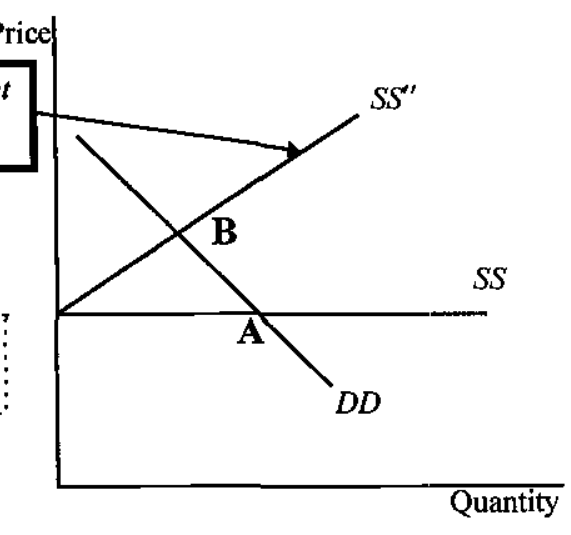

(b) Non-hurricane-exposed contracts

Figure 3: Capital market imperfections and probability updating

A natural way to implement this identification scheme is to regress changes in price and quantity on lagged losses by type, and lagged losses by type interacted with contract exposure by type. If there are $K$ types of catastrophe, the conditional expectation functions takes the form

$$
\begin{aligned}
& \Delta \ln \left(p_{j, t}\right)=\alpha+\sum_{k=1}^{K} \beta_{k} \theta_{,}\left(l_{k}\right)+\sum_{k=1}^{K} \gamma_{k} w_{j, k,} \theta_{t}\left(l_{k}\right)+\varepsilon_{j, t}, \\
& \Delta \ln \left(q_{j, t}\right)=\alpha+\sum_{k=1}^{K} \delta_{k} \theta_{t}\left(l_{k}\right)+\sum_{k=1}^{K} \phi_{k} w_{j, k, t} \theta_{t}\left(l_{k}\right)+\varepsilon_{j, t},
\end{aligned}
$$


where $p_{j, t}$ and $q_{j, t}$ are the price and quantity, respectively, of insurer $j$ 's contract at time $t, \theta_{1}\left(l_{k}\right)$ is a distributed lag of losses of event type $k, w_{j, k, t}$ is the exposure of insurer $j$ to catastrophes of type $k$ at time $t$, and $\varepsilon_{j, \tau}$ is a disturbance term. The relative exposure term, $w_{j, k, t}$, is defined as

$$
w_{j, k, t}=\frac{q_{j, k, t}}{\left(\frac{1}{K}\right) \sum_{k=1}^{K} q_{j, k, t}}
$$

where $q_{j, k,}$ is the absolute exposure (the actuarially expected loss) of insurer $j$ to catastrophes of type $k$ at time $t . \beta_{k}\left(\delta_{k}\right)$ measures the response of contract prices (quantities) to losses of type $k$ independent of contract exposure. The parameter $\gamma_{k}\left(\phi_{k}\right)$ detects the exposure sensitivity of the price (quantity) responses. In estimating (1) and (2), we restrict attention to simple lag structures, such as ${ }^{8}$

$$
\theta_{1}\left(l_{k}\right)=l_{k, t-2}+l_{k, t-3}+l_{k, t-4}+l_{k, t-5}
$$

To the extent that capital-market imperfections are responsible for price and quantity changes, we expect $\beta_{k}>0$ in (1) and $\delta_{k}<0$ in (2), with the null hypothesis of perfect capital markets being $\beta_{k}=0$ and $\delta_{k}=0$. Conditional on a loss from a particular event type, prices tend to rise and quantities to fall equally across all contracts if there are capital market imperfections. The composition of contract exposure only matters for price changes if probability updating is present. Thus, with no probability updating, $\gamma_{k}=0$ for all $k$, and with probability-updating $\gamma_{k}>0$ for all $k$. Of course, if both capital market imperfections and probability updating are important, we expect $\beta_{k}>0$ and $\gamma_{k}>0$.

It is of interest to consider several modifications of the basic specifications (1) and (2). For instance, if the average effect of a dollar of losses is the same across catastrophe types, as the capital market imperfections view would suggest, then we expect $\beta_{1}=\beta_{2}=\ldots=\beta_{K}$. This restriction can readily be imposed in the estimation. A second worthwhile modification is to allow the average and marginal effects of losses to differ. If the supply schedule is nonlinear, for example, then it may be true that large losses have proportionately bigger effects than small losses. Indeed, this is true in most models of capital market imperfections, as discussed in Froot and O'Connell (1997). A convenient way to allow for this possibility is to include higher-order terms in the distributed lag of losses.

\footnotetext{
${ }^{8}$ Losses in the quarter immediately preceding contract inception appear to have no influence on prices. The most likely reason for this is that there can be a delay in the assessing the extent of catastrophe losses. Accordingly, losses lag prices by two or more quarters in all of our analysis.
} 


\subsection{Differentiating among catastrophe types}

We differentiate exposure along two dimensions: by geographic region and by catastrophe type. Distinguishing events across regions is appealing because regional market share data are available for many reinsurance contracts. These market share data provide a ready measure of relative contract exposure. Thus $w_{j, k, t}$ can be defined as

$$
w_{j, k, t}=\frac{m_{j, k, t}}{\left(\frac{1}{K}\right) \sum_{k=1}^{K} m_{j, k, t}}
$$

where $m_{j, k,}$ is the market share of insurer $j$ in region $k$. We estimate (1) and (2) using this measure of exposure in the empirical analysis in Section 6.

There are two drawbacks to this approach, however. First, market shares are typically built up from the share of total catastrophe premiums in a region that go to insurer $j$. To the extent that premiums are a poor proxy for true exposure, $w_{j, k, t}$ will be subject to measurement error. Second, it is clear that the catastrophe occurrences in one region may reveal important information about the distribution of losses in other regions. For example, hurricane losses in the Southeast are likely to lead to probability updates in the distribution of hurricane losses in both the Northeast and Southeast. As a result, price increases (and quantity decreases) in the Northeast in the aftermath of a Florida hurricane could be due to either probability updating or inelastic capital supply to the industry, and identification may be tenuous.

These two shortcomings motivate us to differentiate catastrophes by type as well. Here, the exposure of each contract to distinct classes of events such as earthquakes, hurricanes and winter storms is calculated. This strategy avoids the second shortcoming above. Losses from a particular type of event (e.g. windstorm) are likely to generate little updating in the distributions of other event losses (e.g. earthquake). Thus separate identification of probability-updating and capital market imperfections is more dependable. The cost is that calculating exposures catastrophe type and region entails considerable computational effort. First, the frequency and severity of each type of catastrophe must be estimated by region. Then these distributions must be used to derive the distribution of losses on each contract by simulation. The calculation of contract exposure by catastrophe type is taken up in Section 4, after a discussion of the data and construction of our main variables. 


\section{Data}

Our data is built up from four sources. The basic information on catastrophe reinsurance pricing is provided by Guy Carpenter \& Co. Information on the regional market share of insurers is developed from A. M. Best data on insurance premiums written by company. Our estimates of catastrophe frequency and severity are based on Property Claims Services (PCS) data on U.S. catastrophe losses since 1949. Finally, interest rate and CPI data are collected from Ibbotson and Associates and the IMF respectively.

\subsection{Guy Carpenter catastrophe treaty data}

Our basic data come from Guy Carpenter's proprietary database of catastrophe reinsurance contracts. Guy Carpenter \& Co. is by far the largest U.S. catastrophe reinsurance broker, with a market share of between $30 \%$ and $80 \%$ during our sample. The contracts brokered by Guy Carpenter cover a variety of natural perils, including earthquake, fire, hurricane, winter storm and windstorm.

We examine a total of 489 contracts brokered for 18 national and 19 regional insurers over the period 1970-1994. ${ }^{9}$ The duration of coverage is typically one year. Most contracts have a single mandatory reinstatement provision. ${ }^{10}$ Data on contract inception date, retention (i.e., the retention of the lowermost layer in the contract), limit (i.e., the sum of the limits of all the layers in the contract), and premium (i.e. the sum of the premiums paid for the layers in the contract) are employed. All of the contract inception dates are at the start of a quarter.

\subsection{A. M. Best market share data}

To determine the catastrophe exposure of each contract, we must calculate the distribution of contract losses, a random variable for each contract. To do this, we assume that, within each region, each company's exposure is proportional to insurance industry exposure within the region. We therefore first determine a distribution for insurance industry losses for each region (by event type), and second multiply this aggregate distribution by an individual insurer's market share to determine the distribution

\footnotetext{
${ }^{9}$ Seven very small regional insurers were dropped from the original Guy Carpenter \& Co. data. In some of the computations below, we focus in on a smailer number of national reinsurers, for whom data are available in every year.

${ }^{10}$ The reinstatement provision stipulates that, conditional on an event which triggers losses on the contract, the limit is to mandatorily reinstated (one time only) by the reinsurer after payment of a reinstatement premium by the cedent. It appears that this provision has had only a modest effect on prices, and we ignore its effects. Conversations with brokers suggest that observed prices are approximately $10 \%$ lower than they would have been without the reinstatement premium. This seems surprising (forward contracts are usually priced at zero), but if anything leads us to underestimate what premia would be in the absence of reinstatement provision.
} 
of insurer-specific faced by that company. Using this information, we can calculate the company-specific distribution of losses under each contract.

Our estimates of insurer market shares are developed using data from A. M. Best on insurance premiums written by company, by line-of-business, by state, and by year. We reduce these multiline market shares to regional catastrophe market shares by applying a modified Kiln Formula, which assigns regional weights to premiums in each line of business based on exposure to catastrophes of that line in that region. ${ }^{11}$ For example, depending on the region, anywhere between 50 and 95 percent of homeowners premiums are considered as funding catastrophe exposure. The five US regions used for insurer market shares are the Northeast, Southeast, Texas, the Midwest, and California. ${ }^{12}$ We apply this market share data to all 489 reinsurance contracts selected from the Guy Carpenter \& Co. treaty database.

\subsection{Historic catastrophe loss data from Property Claims Services}

As mentioned above, we need to determine the distribution of industry-wide losses to calculate the catastrophe exposure of each contract. To do this, we estimate the distributions of catastrophe frequency and severity using data from Property Claims Services (PCS). PCS has catalogued all catastrophe losses on an industry-wide basis since 1949 by type and U.S. region. The PCS data are widely used as an industry standard.

Prior to estimating the parameters of the frequency and severity distributions, two adjustments are made to the PCS data. First, the losses are converted to 1994 dollars using the CPI. Second, they are modified to take into account shifts in the portfolios of property exposed to loss over the period. A key component of the latter adjustment is the demographic shift towards California, Florida, and Texas that has characterized recent decades. These two adjustments are carried out by Guy Carpenter \& Co. Both adjustments are important. Indeed, the second adjustment implies that the same size event in real dollars causes damages which have grown on average by $5 \%$ per year over the sample period.

\footnotetext{
"This is a common industry practice. The specific weights used in our Kiln formula are from Guy Carpenter \& Co.

12 The regions are comprised as follows: Northeast-Connecticut, Delaware, Maine, Maryland, Massachusetts, New Hampshire, New Jersey, New York, Pennsylvania, Rhode Island, Vermont; Southeast-Florida, Georgia, Mississippi, North Carolina, South Carolina, Virginia, West Virginia; Texas-Texas; Midwest-Illinois, Indiana, Kentucky, Missouri, Tennessee; California - California.
} 


\subsection{Interest rate and CPI data}

For the purposes of calculating the net present value of payment flows, we use Ibbotson and Associate's index of the return on 30-day U.S. Treasuries. This is collected monthly from 1970:1-1995:4. The U.S. CPI is taken from the IMF's, International Financial Statistics. The frequency is monthly, from 1970:11995:3.

\section{Calculation of exposure and price}

\subsection{Exposure}

In this section, we describe our method of estimating the catastrophe exposure embodied in each excessof-loss contract. The estimation is carried out in three stages. First, the frequency and severity of each type of event and region are estimated by maximum likelihood for particular families of distributions. Second, a simulated event history is generated by repeatedly drawing from the fitted frequency and severity distributions. Finally, the payouts under each contract in each year of event history are calculated. The mean of the distribution of these payouts is our estimate of the "quantity" of reinsurance, $q_{j, k, t}$, embedded in that particular contract.

\subsubsection{The frequency and severity of catastrophes}

The first step towards calculating contract exposure is to estimate the frequency and severity of catastrophes using the adjusted PCS loss data. Altogether there are over 1,100 catastrophes recorded by PCS. These events are classified into 10 categories: earthquake, fire, flood, freeze, hail, hurricane, snowstorm, tornado, thunderstorm and windstorm. ${ }^{13}$ Many of these events are relatively minor: only 557 have adjusted losses in excess of $\$ 15$ million, and only 107 have losses in excess of $\$ 100$ million. Four categories of losses are well-represented in the set of large losses: earthquake, fire, hurricane and windstorm. ${ }^{14}$ As our primary interest is in exposure to large losses, we confine attention to these types. Examination of the data reveals that there is some heterogeneity in the losses that arise from windstorms. In particular, a number of the windstorms refer to winter storms ("Nor'easters") in New England.

\footnotetext{
${ }^{13}$ PCS classifies many events into more than one category. For instance, winter storms in New England, which have on occasion caused substantial damage, are classified first as windstorms, and second as hail, freeze or snowstorm.

${ }^{14}$ During the 1949-1994 sample period, there were no floods, snowstorms or thunderstorms with losses in excess of $\$ 100$ million. Only one freeze had losses in excess of $\$ 100$ million, a $\$ 307$ million freeze in Texas in 1989 . Three hailstorms and three
} 
Accordingly, we split the windstorm category into two subcategories: winter storm, defined to be a windstorm in New England in either the first or fourth quarter, and windstorm, defined to be all other occurrences of a windstorm. ${ }^{15}$

Having defined these five categories of events, we need to make some assumption about regional effects before we can estimate frequency and severity distributions. The simplest assumption would be that, for each catastrophe type, event occurrences are drawn from a single nationwide frequency distribution while loss sizes are drawn from a single nationwide severity distribution. Given the relative paucity of loss information, this approach helps by pooling the available data. However, the assumption of equal regional distributions is likely to be incorrect. For instance, hurricanes are much less likely to occur in California than in Florida, and the majority of earthquakes occur in California.

As a result, we make specific assumptions regarding frequency and severity on the basis of a careful examination of the 1949-1994 catastrophe data. These assumptions are summarized in Table 1. A catastrophe is defined as an event that gives rise to $\$ 15$ million or more in insured losses. Column 2 summarizes the event history for each type. Column 3 reports the regions in which each event type is assumed to occur. Columns 4 and 5 indicate the number of regional frequency and severity distributions estimated for each type. Some of the constraints, such as the assumption that winter storms do not strike California, seem entirely reasonable. Others, such as the assumption that earthquakes do not strike outside California or that winter storms do not hit the Midwest, are less tenable (though see Footnote 15), and are dictated largely by data availability.

With the assumptions described in Table 1, there are 33 frequency distributions to estimate. We assume that the frequencies are Poisson distributed, and estimate the Poisson parameters by maximum likelihood (the estimates are equal to the mean number of events that occur per quarter). Table 2 presents the frequency results in four quarterly arrays, by type and region. The estimated frequencies accord with what one might expect. For example, hurricanes are most likely to occur in the third quarter.

Next we consider severity. There are six severity distributions, one for each of the catastrophe types identified in Table 1. We fit two alternative density functions to the empirical severity distribution of each type. The first is a lognormal distribution, with density function for losses $l$ given by $f(l)=\exp \{-$ $\left.[\ln (l)-\mu]^{2} / 2 \sigma^{2}\right\} /[l \sigma \sqrt{ }(2 \pi)], l>0$. The second is a Pareto distribution, with density function $f(l)=\alpha \beta^{a} / l$ ${ }^{(1+\alpha)}, l>\beta$. Once again, the estimation is carried out by maximum likelihood. The fitted distributions are 
reported in Table 3. For earthquake, winter storm and windstorm events, the likelihood ratio test selects the Pareto distribution as the better fit, while for fire and hurricane events, the lognormal distribution is preferred. However, because the Pareto distribution tends to place a large amount of probability in the right-hand tail of the distribution, it does not perform well in attaching reasonable probabilities to large losses. For example, using the estimated Pareto density, the probability that a hurricane in the Southeast generates $\$ 15$ billion in losses (given that a hurricane occurs) is almost $10 \%$, which appears somewhat high. ${ }^{16}$ It might be preferable, therefore, to use the lognormal fit as the baseline severity distribution for all event types. This is the strategy we adopt. The fitted lognormal distributions are shown in Figure 9 for losses in the range $\$ 0-\$ 3$ billion.

\subsubsection{Simulated event history}

Using these frequency and severity distributions, we are able to simulate an "event history" of catastrophes. From this event history the distribution of payments under each excess-of-loss contract can be obtained.

Of course, it is not necessary to simulate the distribution of contract payments. In principle, it is possible to determine contract payments analytically. However, analytical solutions are complicated because a contract's payment is triggered by only a single event, even though that event could be one of five different peril types. The single-event clause is in effect a knockout provision, allowing the contract to mature following the first event that generates losses in excess of the retention. For example, it may be that earthquakes are the major large risk for an contract to trigger, but a large freeze in the Northeast in early January could trigger the contract, thereby knocking out the earthquake risk for the remainder of the year.

This knockout provision gives the contract a payment distribution that is very different from that which would apply if the contracts were instead written to cover aggregate losses (i.e., the sum of losses across events). It can also give rise to some paradoxical effects. For example, an increase in the frequency of winter storms may actually reduce the total exposure embodied in a single-event contract, since it may increase the probability that it matures following a winter storm rather than a devastating hurricane. We look briefly at the value of the knockout provision in the Appendix.

\footnotetext{
${ }^{15}$ The assumption that winter storms do not afflict the Midwest may seem strange. The reason is that our regional market share data is calculated for the Midwest using only five states: Illinois, Indiana, Kentucky, Missouri, Tennessee. The Dakotas, Michigan, Minnesota, Wisconsin and other characteristically Midwestern states are excluded.

${ }^{16}$ Using PCS data, Cummins, Lewis and Phillips argue elsewhere in this volume that the Pareto distribution tends to overestimate the probability in the tail of catastrophe severity distributions, and that the lognormal fit is to be preferred on these grounds.
} 
We simulate a 1,250-year event history. For each quarter, the following steps are performed:

1. The number of events of each type that occur in each region is randomly drawn from the relevant Poisson frequency distribution (Table 2);

2. For each event that occurs, a loss amount is randomly drawn from the relevant severity distribution (Table 3);

3. All the events that occur in the quarter are randomly sequenced in time.

The random sequencing of the events throughout the quarter is an approximation, at best. It is likely, for example, that winter storms occur more frequently in January than March. While it would be preferable to sequence the events on a time scale finer than quarterly, too few events that have occurred since 1949 to allow estimation of this.

\subsubsection{Contract exposure}

The exposure of each excess-of-loss contract in our data can be calculated by examining its loss experience in each year of the simulated event history. To take an example, suppose we are considering a contract brokered by a national insurer with an April 1 inception date. Let $L$ and $R$ be the contract's limit and retention, and let $m_{j, k}, k \in\{\mathrm{NE} \mathrm{SE} \mathrm{TX} \mathrm{MW} \mathrm{CA}\}$ be the $j$ th insurer's market share in each of the five regions. The contract's exposure is measured as follows:

1. Split the event history into 1,249 year-long periods measured from April 1 to March 31 .

2. Consider each period in turn. If no event occurs in a period, move to the next period. Otherwise consider each event in sequence.

(a) Let the first event be in region $k$, and let insured losses from this event be $l$.

(b) If $m_{j, k} l>R$, the contract is triggered. Measure the reinsurance payment for this period as $\min \left(L, m_{j, k} l-R\right)$, and move on to the next period. The contract is no longer in force.

(c) If $m_{j, k} l<R$, no payment takes place, and the contract remains in force. Move on to the next event, or the next period if there are no more events.

This algorithm generates 1,249 observations on the distribution of payments under the contract. The first moment of this distribution is the expected exposure to catastrophe losses. It is easy to derive various conditional loss distributions from the unconditional distribution, such as the distribution of hurricane losses, or the distribution of losses from events in the Northeast. 


\subsection{Contract quantity and price}

We label the expectation of the unconditional distribution $q_{j, t}$, the exposure embodied in company $j$ 's contract at time $t$. This is interpreted as the quantity of reinsurance purchased. By considering only those reinsurance payments that occur following particular types of catastrophes, it is possible to use the same algorithm to calculate the contract's exposure to each of the catastrophe types listed in Table 1. These exposures by type form the inputs to the calculation of loss weightings in Equation (3).

To calculate contract price, we begin with the premium paid for each contract. This is simply measured as the sum of the premiums paid for each layer. Typically, the premiums are paid on a quarterly basis over the duration of the contract. We discount these premium flows back to the contract inception date using the three-month Treasury Bill rate. By using the riskless rate, we are equating actuarial present values with true value. Strictly speaking, this assumption holds only under risk-neutral pricing and in the absence of insurer credit risk. However, given that catastrophe losses are uncorrelated with total wealth, risk neutral pricing is not easily rejected. Furthermore, the use of a risk-adjusted discount rate would, in practical terms, have little import for our results.

Once the NPV of the premiums is calculated, it is converted to 1994 dollars using the CPI deflator. Our measure of price is the net present value (NPV) of premiums divided by contract exposure. Thus the price of company $j$ 's contract at time $t$ is

$$
p_{j, \iota}=\frac{\mathrm{NPV}(\text { Premiums })}{q_{j, t}}
$$

\section{Graphical analysis}

We are now in a better position to understand the data and computations behind Figure 4 and Figure 5 . They plot, respectively, the industry quantity and price series quarterly from 1975:1-1993:4. The quantity series is the simple sum of exposure across companies. The price series is the exposureweighted average of the prices of all contracts in force in that quarter. ${ }^{17}$ Note that Figure 5 shows that risk was sometimes ceded at less than actuarial value (i.e. $p_{j, t}<1$ ) during the 1970 s and early 1980 s.

Hurricane Andrew is responsible for the largest catastrophe loss during our sample period. In light of this, it is of interest to look at the time series of prices around the time of this event. In particular, we can

\footnotetext{
${ }^{17}$ This industry series is based on the contract prices for four insurers that purchased reinsurance through Guy Carpenter \& Co. in every year from 1975 to 1993 . It is representative of the behavior of prices for the other insurers in our database.
} 
differentiate between the price-quantity reactions of those contracts heavily exposed to hurricane risk/Southeast risk and those with relatively less exposure. Table 4 contrasts the price and quantity responses. From Panel (a), we see that even those contracts with zero market share in the Southeast show large increases in price in the wake of Andrew. This is supportive of the capital market imperfections view. However, as already discussed, even if there are no other losses occurring at this time, these price responses may be the result of probability updating if the Andrew loss experience revealed new information about hurricane exposure in other regions. Panel (b) investigates this by sorting contracts according to their hurricane exposure. It turns out that it is those contracts least exposed to hurricane losses that exhibit the largest increase in price. Taken at face value, this suggests that capital market imperfections, and not probability updating, are the most important determinant of the price responses. In order to shed more light on this question, we need to estimate the conditional expectation functions (1) and (2).

\section{Estimation}

\subsection{Exposure measured by regional market share}

In this subsection we differentiate events by region, and estimate (1) and (2) using regional market shares as proxies for regional exposure. Eight variants of the base specification are estimated, corresponding to different assumptions about the functional form through which losses affect prices. The results are shown in Table 5 and Table 6.

Turning to the price regressions first, the $\beta_{k}$ are positive and statistically significant in all specifications. The $\gamma_{k}$ are positive, but generally not very significant. This is prima facie evidence that both capital market imperfections and probability updating play some role in determining the response of price to catastrophe losses. However, in all cases the coefficient on unweighted losses is larger and more statistically precise than that on exposure-weighted losses. This suggests that the supply-side capital market channel is the more dominant of the two.

To get a sense for magnitudes, suppose that a $\$ 10$ billion event occurs in a particular region. Using the first price specification (which uses 2 quarters of lagged losses), the $\$ 10$ billion loss increases all contract prices in the next year by an average of about 19 percent. Notice that this price increase is independent of contract exposure to the region. Higher exposure to the affected region leads to further, but much smaller, increases in price. A firm that increases its share of the market of the affected region 
from 0 to 100 percent sees its reinsurance price increase by an average of 4 percent. Thus, much of the increase in price appears to be due to a decline in the supply of reinsurance (or to increases in expected losses outside of the affected region). Probability updating and capital-market imperfections both help, but the capital market effects seem much larger.

Table 5 also reports results from Equation (2), where quantity reinsured is the dependent variable. The results here are consistent with those above: the coefficients on unweighted losses provide strong evidence of capital-market imperfections. The $\delta_{k}$ coefficients are negative and statistically less than zero at the 10 percent level in all cases. As we expect from Figure 1 through Figure 3, the $\phi_{k}$ coefficients on market-share weighted losses are ambiguous in sign.

To calibrate, the first quantity specification suggests that a $\$ 10$ billion loss in a particular region leads to a decline in quantity 5.2 percent on average over the next year. Meanwhile, for the same size loss, a company which has 100 percent market share in the affected region on average purchases 0.4 percent less reinsurance than if it had a 0 percent market share. Note, however, that this latter effect is neither economically nor statistically significant. In other words, we cannot reject the hypothesis that relative exposure levels have no effect on quantity purchased. But we can reject the hypothesis that purchases do not decline on average subsequent to an event. The quantity results are therefore most consistent with the capital-market imperfections story.

In Table 6 we relax the restriction that all the $\gamma_{k}$ and $\phi_{k}$ coefficients are equal. This allows the probability updating effect to differ by region. Indeed, there is some evidence for this in the coefficient estimates, which differ substantially across regions. Here there is somewhat stronger evidence of probability updating. The cumulative sum of regional losses over the last 4 quarters appears to impact positively on price in all cases. Nonetheless unweighted losses in each region continue to impact price positively and quantity negatively. All but two of these estimates are statistically significant.

\subsection{Exposure measured by actuarially expected loss}

The specifications in Table 7 and Table 8 are analogous to those in Table 5 and Table 6. However, here we use actuarial exposures to weight losses. As discussed earlier, probability updating may occur across, rather than within, regions, and this complicates the identification of capital market effects using regional market shares. By distinguishing losses by type rather than region, we can separately identify capitalmarket and probability-updating effects on prices.

The results in Table 7 and Table 8 are in line with what we found in the previous two tables. First, the unweighted losses in the price equations enter positive and significantly, the coefficients having even 
larger signs. Specification 1, for example, reveals that a $\$ 10$ billion event tends to increase prices by over 40 percent in the following year. Moreover, the aggregated $\gamma$ coefficient on event-exposure weighted losses is not positive in the price equations, suggesting that the unweighted losses account for all of explainable price increases subsequent to events. Second, the unweighted losses in the quantity regressions enter negatively, and statistically significant in 3 of the 4 regressions. This is again consistent with capital-market imperfections. Indeed, the coefficient is large, suggesting that a $\$ 10$ billion event reduces the quantity of reinsurance purchased by between 8 and 16 percent. There is no evidence supporting the presence of event-specific probability updating in Table 6.

Table 7 provides similar results. Unweighted losses influence prices positively and quantities negatively (though not significantly). Squared losses do not seem to have the expected effects, suggesting that large losses may not have proportionately as large effects as smaller losses in the data.

Taken together, these results provide evidence to support the existence of both imperfections in capital supply and probability updating. However, it is the former that accounts for the bulk of price movements in the wake of losses.

\section{Conclusion}

There are at least two candidate explanations for the sharp rise in catastrophe reinsurance prices and retentions that occurred in the $1990 \mathrm{~s}$, a time of unprecedented catastrophe losses. The first holds that capital market imperfections impeded the flow of capital into the reinsurance sector. In the presence of these imperfections, prices are bid up and quantities fall due to the supply contractions that accompany losses. The second explanation is that the changes in prices and quantities have largely been the result of an increase in the perceived frequency or severity of catastrophes. If, after a loss, neither supply nor demand shifts, but actuarial probabilities of losses tend to increase, then we would observe price increases and quantity reductions since our quantity measure is derived from time-invariant loss distributions).

To separate out the effects of capital market imperfections and probability updating, we consider two specifications of how loss distributions are updated. First, we assume that probability updating occurs on a region-specific basis, so that event losses in a given region may increase perceived future losses within that region, but not in other regions. Second, we assume that probability updating occurs within (but not across) event types, so that event losses associated with a particular peril may increase perceived future losses from that peril, but not losses associated with other perils. 
We estimate these specifications using detailed reinsurance contract data from Guy Carpenter \& Co. Our findings suggest that, subsequent to losses, price increases and quantity declines are more pervasive across contracts than they should be based on contract-specific exposures to event types and regions. Since cross-sectional variation in exposures should explain changes in prices and quantities, but doesn't, it appears that price shocks are highly correlated across all forms of catastrophe exposure. This lends support to the view that aggregate price and quantity shocks stem from shifts in the supply of capital to the industry. Since reinsurers are financial intermediaries with relatively few fixed factors besides financial capital, the existence of such shifts in supply is evidence of capital market imperfections. 


\section{Appendix: The value of the knockout provision in single-event contracts}

Using the simulated event history, it is possible to measure the value of the knockout provision that is implicit in single-event contracts. This knockout feature stems from the fact that it is the first event occurrence that triggers the contract. ${ }^{18}$ Table Al illustrates how the knockout feature affects expected payouts under various contract provisions. Panel (a), Columns (i) to (vi) consider contracts whose payouts are contingent on the occurrence of particular types of catastrophes. For example, in Column $(i)$, the contract can only be triggered by earthquake losses in excess of the retention. Column (viii) gives the expected payout on a contract that is structured in the same way as the Guy Carpenter \& Co. treatiesi.e., it pays out on the first event of any type that generates losses in excess of retention. The table shows that the sum of the expected payouts on event-specific contracts (Column (vii)) exceeds the expected payout on the all-type contract. This is the familiar result that, with imperfectly correlated risks, it is cheaper to buy insurance on a portfolio than it is to buy a portfolio of insurance policies. Panel (b) of the table is structured in the same way, except that it distinguishes events by region rather than by type. Once again, the sum of the expected payouts on the region-specific contracts exceeds that on the all-region contract.

It is noteworthy that in both cases, the inception date of the contract has only a minor influence on the distribution of payouts.

\footnotetext{
${ }^{18}$ The complexities introduced by the knockout provision form part of the reason why the catastrophe options that trade on the Chicago Board of Trade are written as aggregate rather than single-event contracts.
} 


\section{References}

Cummins, J. D. and P. Danzon, 1991, Price shocks and capital flows in liability insurance, in J. D. Cummins, S. E. Harrington and R. W. Klein (eds.), Cycles and crises in property/casualty insurance: causes and implications for public policy, Kansas City, MO, National Association of Insurance Commissioners.

Cummins, J. D. and J. F. Outreville, 1987, An international analysis of underwriting cycles in property liability insurance, Journal of Risk and Insurance, 54, 246-262.

Froot, K. A., 1995, "Incentive Problems in Financial Contracting: Impacts on Corporate Financing, Investment, and Risk Management Policies" in The Global Financial System, Harvard Business School Press.

Froot, K. A. and P. G. J. O'Connell, 1997, On the pricing of intermediated risks: Theory and application to catastrophe reinsurance.

Froot, K. A. and J. Stein, 1995, Risk Management, Capital Budgeting and Capital Structure Policy for Financial Institutions: An Integrated Approach, NBER Working Paper no. 5403, November.

Gron, A., 1994, Capacity constraints and cycles in property-casualty insurance markets, RAND Journal of Economics 25(1), 110-127.

Gron, A. and D. Lucas, 1995, External financing and insurance cycles, NBER Working Paper No. 5229.

Winter, R. A., 1988, The liability crisis and the dynamics of competitive insurance markets, Yale Journal on Regulation 5, 455-500. 


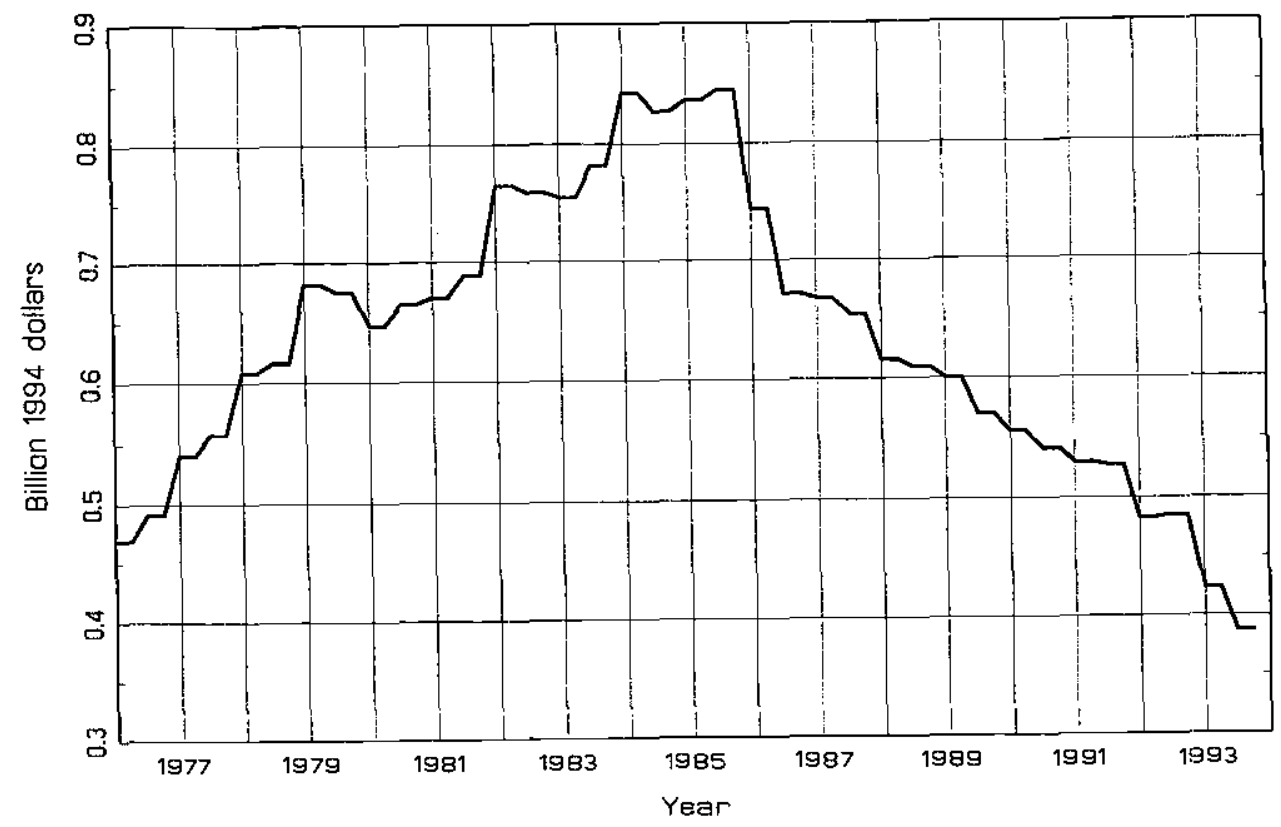

Figure 4: Real quantity of catastrophe exposure ceded, 1975:1-1993:4 ${ }^{19}$

${ }^{19}$ In any quarter, the series is the sum of the contract exposure that is ceded by four major insurers in that quarter. The four companies represent approximately 10 percent of the market. 


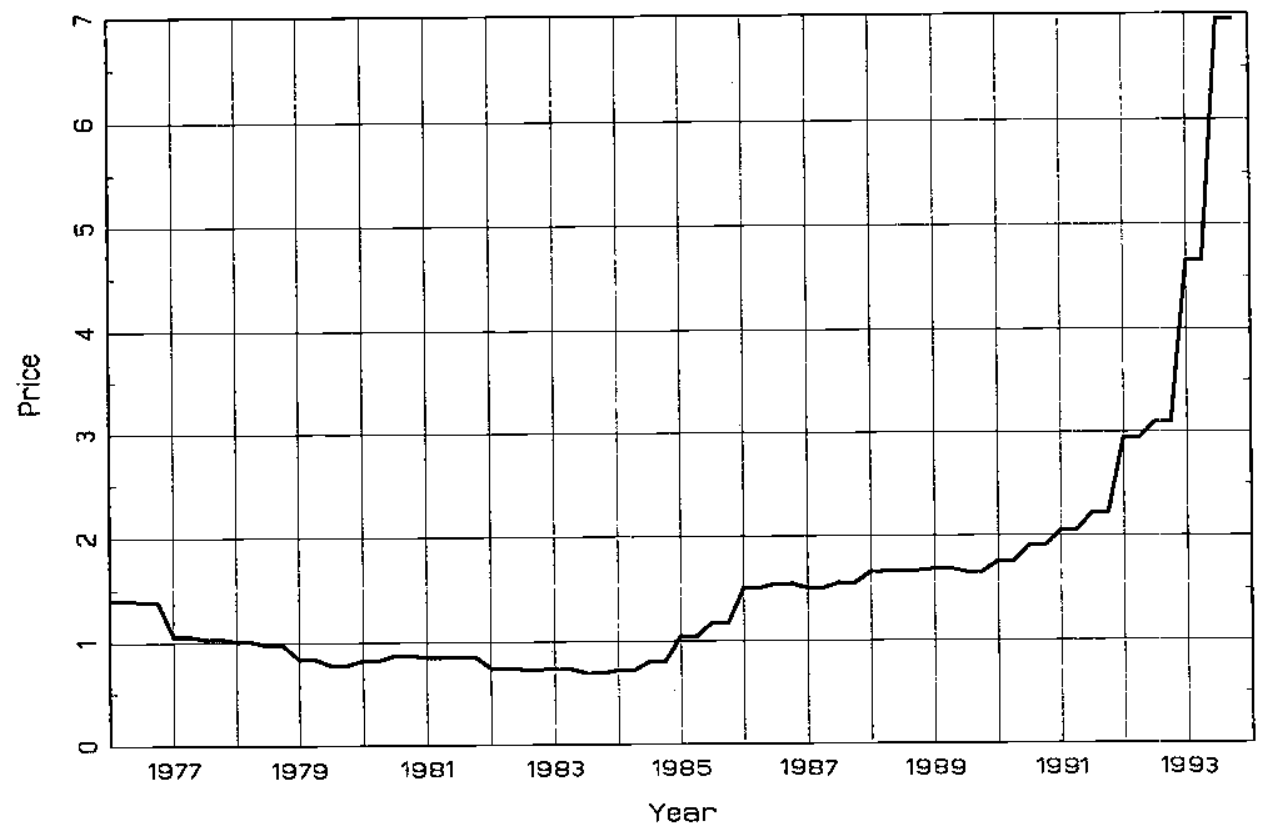

Figure 5: Industry price per unit of ceded exposure, 1975:1-1993:4 


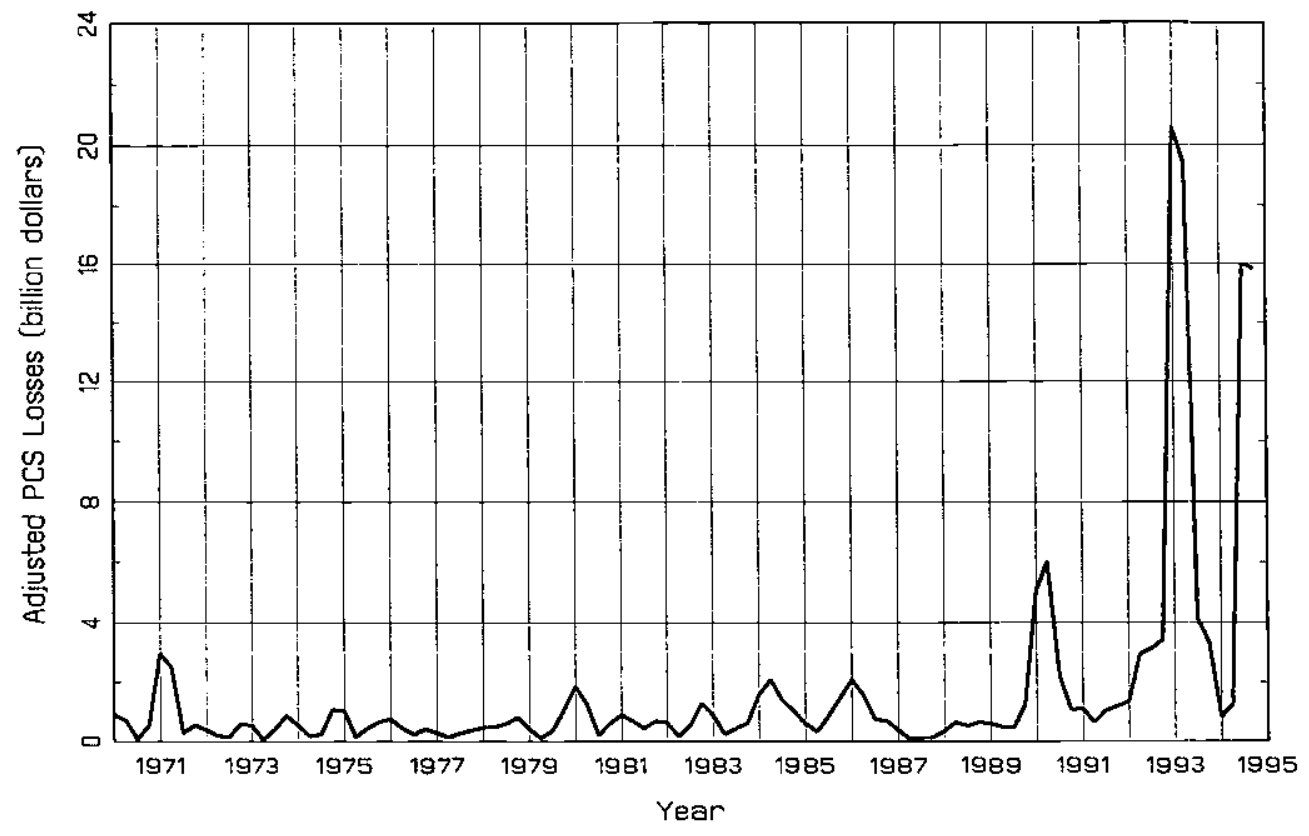

Figure 6: Total adjusted PCS losses by quarter, 1970:1-1994:4 


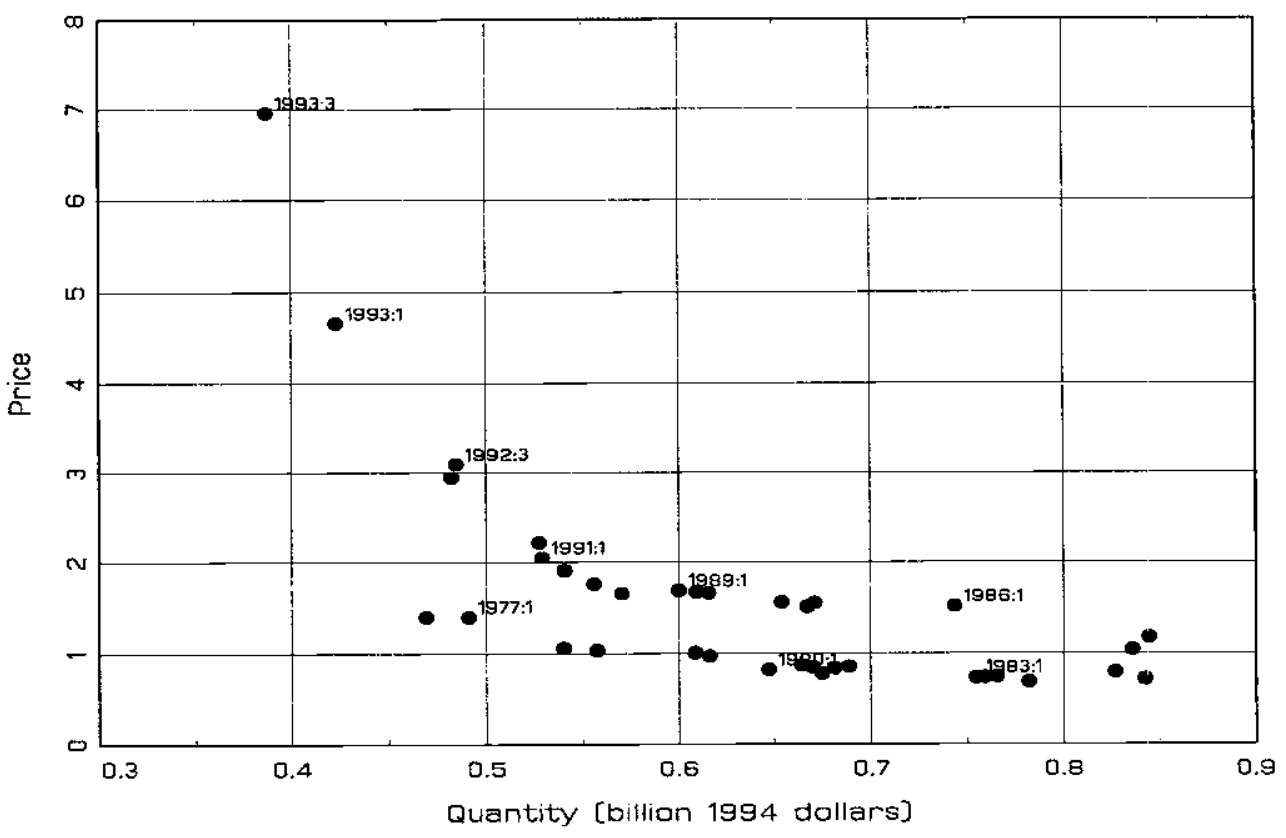

Figure 7: Industry price-quantity pairs, 1975:1-1993:4 


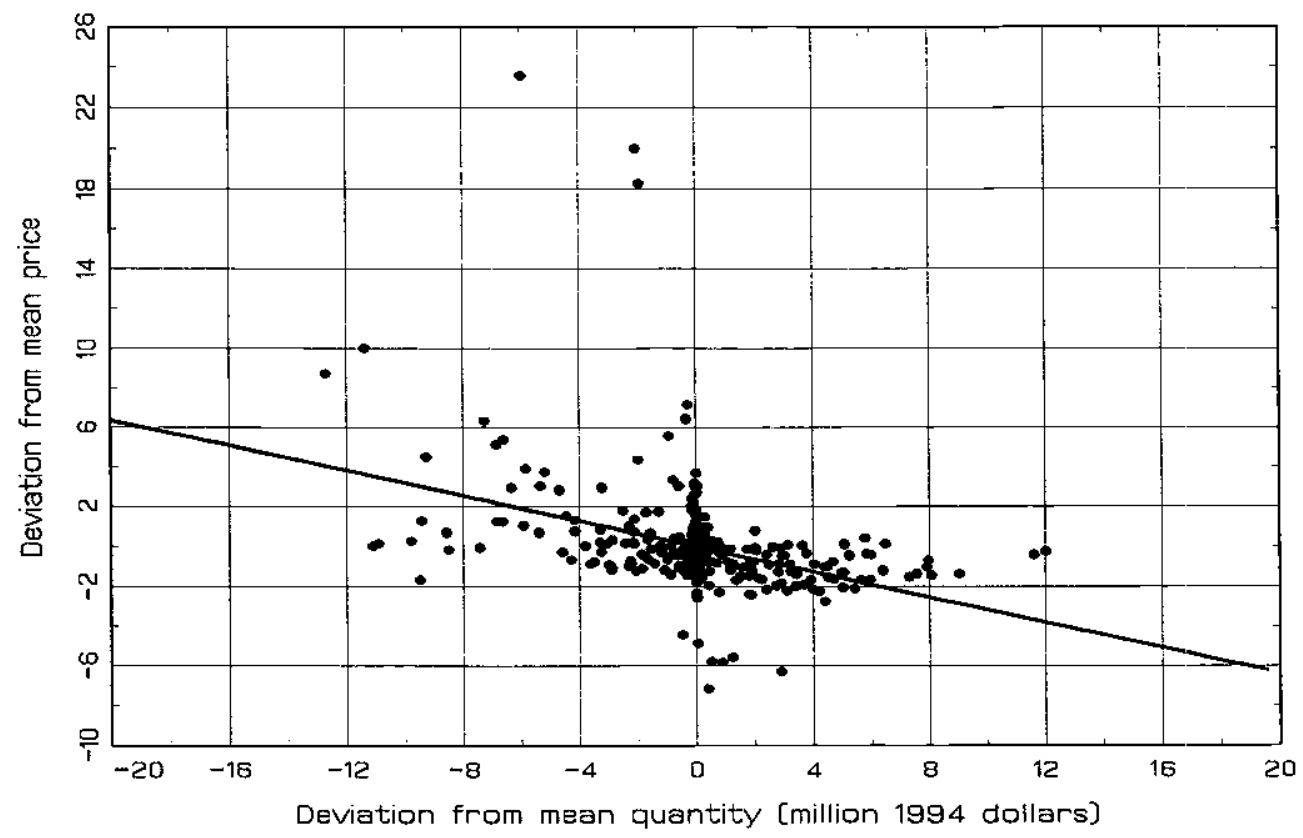

Figure 8: Contract-by-contract price-quantity pairs, demeaned by company, 1970-1994. Linear fit estimated by OLS. 

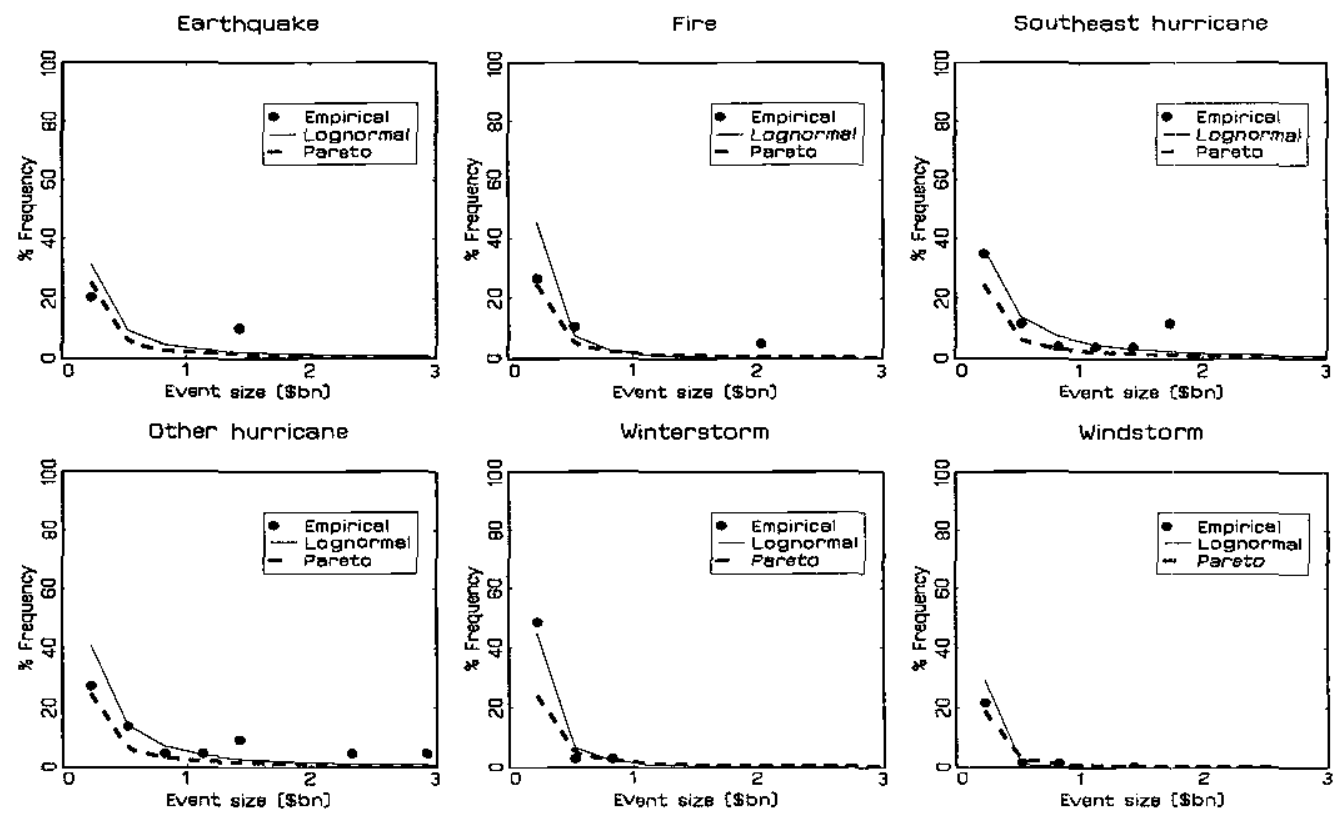

Figure 9: Fitted severity distributions by catastrophe type, 1949-1994 
Table 1: Frequency and severity assumptions by catastrophe type

\begin{tabular}{|c|c|c|c|c|}
\hline \multirow[t]{2}{*}{ Type } & \multirow[t]{2}{*}{ Description of PCS data } & \multicolumn{3}{|c|}{ Assumptions } \\
\hline & & Regions & $\begin{array}{l}\text { Frequency } \\
\text { (\# of regional } \\
\text { distributions) }\end{array}$ & $\begin{array}{c}\text { Severity } \\
\text { (\# of regional } \\
\text { distributions) }\end{array}$ \\
\hline Earthquake & $\begin{array}{l}10 \text { events, all in CA. Frequency appears } \\
\text { throughout year. }\end{array}$ & $\mathrm{CA}$ & $\begin{array}{l}\text { 1: Uniform } \\
\text { across quarters }\end{array}$ & 1 \\
\hline Fire & $\begin{array}{l}19 \text { events, } 12 \text { in CA, } 2 \text { in } \mathrm{MW}, 3 \text { in NE, } 2 \\
\text { in SE. Frequency higher in fourth quarter, } \\
\text { and different for CA. Severity comparable } \\
\text { across events. }\end{array}$ & $\mathrm{NE}, \mathrm{MW}, \mathrm{CA}$ & $\begin{array}{l}\text { 2: CA and } \\
\text { NE/SE/MW/ } \\
\text { TX. Both } \\
\text { uniform across } \\
\text { quarters }\end{array}$ & 1 \\
\hline Hurricane & $\begin{array}{l}48 \text { events, } 26 \text { in SE, } 22 \text { in NE and TX. } \\
\text { Most in third quarter. More severe in } \\
\text { Southeast. }\end{array}$ & NE, SE, TX & $\begin{array}{l}\text { 8: SE (4 } \\
\text { quarterly) and } \\
\text { NE/TX (4 } \\
\text { quarterly) }\end{array}$ & $\begin{array}{l}\text { 2: Southeast, } \\
\text { Northeast/ } \\
\text { Texas }\end{array}$ \\
\hline Winter storm & 35 events, in NE in quarters 1 or 4 & $\mathrm{NE}$ & $\begin{array}{l}\text { 1: uniform } \\
\text { across quarters } \\
1 \text { and } 4\end{array}$ & 1 \\
\hline Windstorm & $\begin{array}{l}352 \text { events, all regions. Frequency differs } \\
\text { across regions, but severity is comparable }\end{array}$ & $\begin{array}{l}\text { NE, SE, TX, } \\
\text { MW, CA }\end{array}$ & $\begin{array}{l}\text { 20: one for } \\
\text { each region } \\
\text { and quarter }\end{array}$ & 1 \\
\hline
\end{tabular}

Assumptions for catastrophe frequency and severity distributions, based on catastrophe experience 1949--1994. A catastrophe is defined as an event that gives rise to $\$ 15$ million or more in insured losses. Column 2 gives a description of catastrophe occurrence by type, 1949-1994. NE denotes northeast, SE southeast, TX Texas, MW Midwest and CA California. Columns 3, 4, and 5 give the assumptions concerning the frequency and severity distributions. The number in the frequency and severity columns represents the number of separately-estimated distributions for that type. For example, the number "I" implies that all regions are pooled, and that a single, nationwide distribution is estimated. 
Table 2: Frequency of catastrophes, measured by their Poisson parameters, by quarter, type and region, 1949-1994

\begin{tabular}{|c|c|c|c|c|c|c|c|c|c|c|}
\hline & $\mathrm{NE}$ & SE & TX & MW & $\mathrm{CA}$ & $\mathrm{NE}$ & $\mathrm{SE}$ & $\mathrm{TX}$ & MW & $\mathrm{CA}$ \\
\hline & \multicolumn{5}{|c|}{ January-March } & \multicolumn{5}{|c|}{ April-June } \\
\hline Earthquake & & & & & 0.054 & & & & & 0.054 \\
\hline Fire & 0.031 & 0.031 & 0.031 & 0.031 & 0.125 & 0.031 & 0.031 & 0.031 & 0.031 & 0.125 \\
\hline Hurricane (SE) & & 0.000 & & & & & 0.043 & & & \\
\hline Hurricane (NE/TX) & 0.000 & & 0.000 & & & 0.033 & & 0.033 & & \\
\hline Winter storm & 0.380 & & & & & & & & & \\
\hline \multirow[t]{2}{*}{ Windstorm } & & 0.652 & 0.326 & 0.500 & 0.304 & 0.196 & 0.457 & 1.109 & 0.935 & 0.000 \\
\hline & \multicolumn{5}{|c|}{ July-September } & \multicolumn{5}{|c|}{ October-December } \\
\hline Earthquake & & & & & 0.054 & & & & & 0.054 \\
\hline Fire & 0.031 & 0.031 & 0.031 & 0.031 & 0.125 & 0.031 & 0.031 & 0.031 & 0.031 & 0.125 \\
\hline Hurricane (SE) & & 0.370 & & & & & 0.130 & & & \\
\hline Hurricane (NE/TX) & 0.283 & & 0.283 & & & 0.033 & & 0.033 & & \\
\hline Winter storm & & & & & & 0.380 & & & & \\
\hline Windstorm & 0.174 & 0.065 & 0.152 & 0.326 & 0.000 & & 0.283 & 0.326 & 0.370 & 0.130 \\
\hline
\end{tabular}

Poisson parameter is equivalent to the mean number of catastrophe occurrences per quarter by type and region. If the frequency of each catastrophe type in each region is Poisson distributed $-f(n)=e^{-\lambda} \lambda^{n} / n !$, where $n$ is the number of events that occur then the numbers in the table are the maximum likelihood estimates of $\lambda$. NE denotes Northeast, SE Southeast, TX Texas, MW Midwest and CA California. Blank elements of the arrays are 0 by assumption (see Table 1). 
Table 3: Fitted severity distributions by catastrophe type, 1949-1994.

\begin{tabular}{|c|c|c|c|c|c|c|c|}
\hline Distribution & Parameter & Earthquake & Fire & $\begin{array}{l}\text { Hurricane } \\
\text { (SE) }\end{array}$ & $\begin{array}{l}\text { Hurricane } \\
\text { (NE/TX) }\end{array}$ & $\begin{array}{l}\text { Winter } \\
\text { storm }\end{array}$ & Windstorm \\
\hline$n$ & & 10 & 19 & 26 & 22 & 35 & 352 \\
\hline \multirow[t]{5}{*}{ Lognormal } & $\mu$ & -2.100 & -2.350 & -1.233 & -1.454 & -2.440 & -3.039 \\
\hline & $\sigma$ & 1.964 & 1.196 & 1.610 & 1.454 & 1.166 & 0.859 \\
\hline & Mean $\log -L$ & 0.006 & 0.752 & -0.662 & -0.340 & 0.867 & 1.772 \\
\hline & $\operatorname{Pr}(l>\$ 5 \mathrm{bn}) \%$ & 2.915 & 0.046 & 3.870 & 1.760 & 0.025 & 0.000 \\
\hline & $\operatorname{Pr}(l>\$ 15 \mathrm{bn}) \%$ & 0.684 & 0.001 & 0.718 & 0.211 & 0.000 & 0.000 \\
\hline \multirow[t]{5}{*}{ Pareto } & $\alpha$ & 0.476 & 0.541 & 0.337 & 0.364 & 0.568 & 0.862 \\
\hline & $\beta$ & 0.015 & 0.015 & 0.015 & 0.015 & 0.015 & 0.015 \\
\hline & Mean $\log -L$ & 0.358 & 0.735 & -0.854 & -0.556 & 0.875 & 1.891 \\
\hline & $\operatorname{Pr}(l>\$ 5 \mathrm{bn}) \%$ & 6.288 & 4.327 & 14.110 & 12.057 & 3.684 & 0.670 \\
\hline & $\operatorname{Pr}(l>\$ 15 \mathrm{bn}) \%$ & 3.727 & 2.389 & 9.743 & 8.082 & 1.973 & 0.260 \\
\hline
\end{tabular}

Results from fitting of lognormal and Pareto distributions to PCS event losses. PCS losses have been adjusted for inflation and population movements by Guy Carpenter \& Co. A catastrophe event is defined giving rise to insured losses in excess of $\$ 15$ million. The density function for the lognormal is $f(l)=\exp \left\{-[\ln (l)-\mu]^{2} / 2 \sigma^{2}\right\} /[l \sigma \sqrt{ }(2 \pi)], l>0$, while the density function for the Pareto is $f(l)=\alpha \beta^{a} / l^{(1+\alpha)}, l>\beta$. The parameters $\mu, \sigma$, and $\alpha$ (not $\beta$, which is a fixed scale parameter set equal to $\left.\$ 15,000,000\right)$ are estimated by maximum likelihood. For a given catastrophe type, estimated mean log-likelihoods for the two distributions are comparable, and provide a means for choosing between them. The table also shows the probability that an event produces insured losses in excess of $\$ 5$ billion and $\$ 15$ billion respectively. 
Table 4: Event study of hurricane Andrew

\begin{tabular}{|c|c|c|c|c|c|c|}
\hline \multirow{4}{*}{$\begin{array}{l}5 \text { most-exposed insurers } \\
5 \text { least-exposed insurers }\end{array}$} & \multicolumn{3}{|c|}{ (a) Southeast exposure } & \multicolumn{3}{|c|}{ (b) Hurricane exposure } \\
\hline & $\begin{array}{c}\text { Mean } \\
\text { exposure }\end{array}$ & $\begin{array}{c}\text { Mean } \\
\Delta \ln \left(p_{j, t}\right)\end{array}$ & $\begin{array}{c}\text { Mean } \\
\Delta \ln \left(q_{j, i}\right)\end{array}$ & $\begin{array}{l}\text { Mean } \\
\text { exposure }\end{array}$ & $\begin{array}{c}\text { Mean } \\
\Delta \ln \left(p_{j, t}\right)\end{array}$ & $\begin{array}{c}\text { Mean } \\
\Delta \ln \left(q_{j, t}\right)\end{array}$ \\
\hline & 0.707 & 0.310 & 0.085 & 0.654 & 0.270 & -0.030 \\
\hline & 0.000 & 0.334 & -0.011 & 0.218 & 0.557 & -0.138 \\
\hline
\end{tabular}


Table 5: The response of price and quantity to losses, exposure measured by regional market shares

\begin{tabular}{lccccccccc}
\hline & \multicolumn{2}{c}{$\sum_{s=1}^{2} l_{k, t-s-1}$} & \multicolumn{2}{c}{$\sum_{s=1}^{2} l_{k, t-s-1}^{2}$} & $\sum_{s=1}^{4} l_{k, t-s-1}$ & \multicolumn{2}{c}{$\sum_{s=1}^{4} l_{k, t-s-1}^{2}$} \\
\cline { 2 - 9 }$\Sigma_{k} \theta\left(l_{k}\right)$ & $\Delta \ln \left(p_{j, t}\right)$ & $\Delta \ln \left(q_{j, t}\right)$ & $\Delta \ln \left(p_{j, t}\right)$ & $\Delta \ln \left(q_{j, t}\right)$ & $\Delta \ln \left(p_{j, t}\right)$ & $\Delta \ln \left(q_{j, t}\right)$ & $\Delta \ln \left(p_{j, t}\right)$ & $\Delta \ln \left(q_{j, t}\right)$ \\
& 1.865 & -0.518 & 0.103 & -0.028 & 1.736 & -0.284 & 0.109 & -0.019 \\
$\Sigma_{k} w_{k} \theta\left(l_{k}\right)$ & $(0.449)$ & $(0.300)$ & $(0.027)$ & $(0.018)$ & $(0.326)$ & $(0.202)$ & $(0.020)$ & $(0.011)$ \\
$R^{2}$ & 0.372 & -0.039 & 0.014 & -0.001 & 0.519 & -0.169 & 0.021 & -0.006 \\
$N$ & $(0.261)$ & $(0.160)$ & $(0.013)$ & $(0.009)$ & $(0.249)$ & $(0.149)$ & $(0.013)$ & $(0.008)$ \\
& 0.140 & 0.012 & 0.096 & 0.008 & 0.263 & 0.019 & 0.230 & 0.015 \\
& 435 & 435 & 435 & 435 & 435 & 435 & 435 & 435
\end{tabular}

OLS estimates of price and quantity response regressions. The dependent variables are 100 times the change in the natural logarithm of contract price and 100 times the change in the natural logarithm of quantity. Losses are measured in billions of dollars. Exposure to each type of regional losses $(w)$ is measured by regional market shares, as in Equation (5). Each column corresponds to a separate regression. Four different assumptions are made about the functional form of distributed lag of losses that affects prices. In Columns 1 and 2 , the loss variable is simply the sum of two lagged quarterly losses, in Columns 3 and 4 it is the sum of squared losses from two lagged quarters, in Columns 5 and 6 it is the sum of four lagged quarterly losses, and in Columns 7 and 8 it is the sum of squared losses from four lagged quarters.

Table 6: The response of price and quantity losses, exposure measured by regional market shares

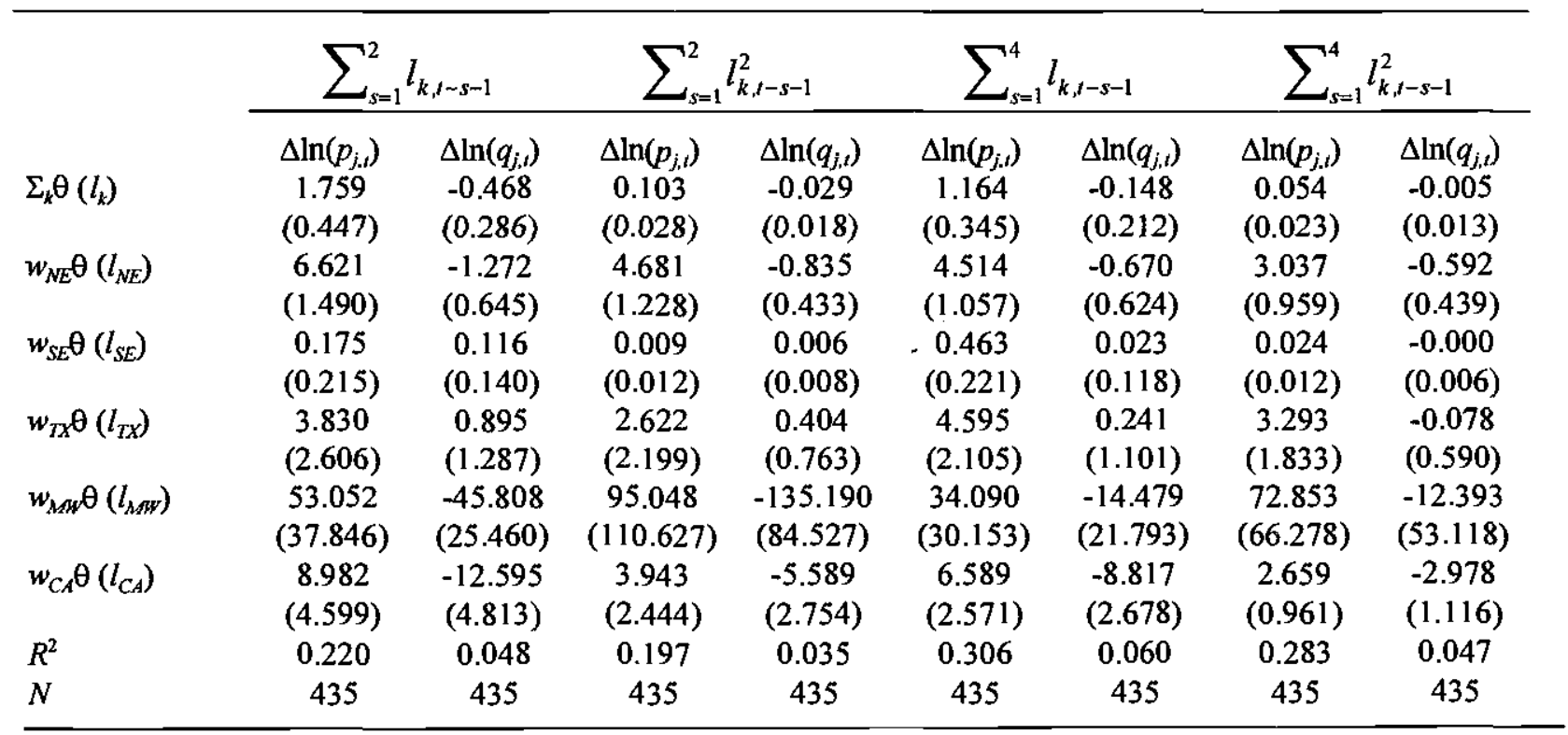

OLS estimates of price and quantity response regressions. The dependent variables are 100 times the change in the natural logarithm of contract price and 100 times the change in the natural logarithm of quantity. Losses are measured in billions of dollars. Exposure to each type of regional losses $(w)$ is measured by regional market shares, as in Equation (5). Each column corresponds to a separate regression. Four different assumptions are made about the functional form of distributed lag of losses that affects prices. In Columns 1 and 2, the loss variable is simply the sum of two lagged quarterly losses, in Columns 3 and 4 it is the sum of squared losses from two lagged quarters, in Columns 5 and 6 it is the sum of four lagged quarterly losses, and in Columns 7 and 8 it is the sum of squared losses from four lagged quarters. NE denotes Northeast, SE Southeast, TX Texas, MW Midwest, and CA California. 
Table 7: The response of price and quantity to losses, exposure measured directly by catastrophe type

\begin{tabular}{lccccccccc}
\hline & \multicolumn{2}{c}{$\sum_{s=1}^{2} l_{k, t-s-1}$} & \multicolumn{2}{c}{$\sum_{s=1}^{2} l_{k, t-s-1}^{2}$} & \multicolumn{2}{c}{$\sum_{s=1}^{4} l_{k, t-s-1}$} & $\sum_{s=1}^{4} l_{k, t-s-1}^{2}$ \\
\cline { 2 - 9 }$\Sigma_{k} \theta\left(l_{k}\right)$ & $\Delta \ln \left(p_{j, t}\right)$ & $\Delta \ln \left(q_{j, t}\right)$ & $\Delta \ln \left(p_{j, t}\right)$ & $\Delta \ln \left(q_{j, t}\right)$ & $\Delta \ln \left(p_{j, t}\right)$ & $\Delta \ln \left(q_{j, l}\right)$ & $\Delta \ln \left(p_{j, t}\right)$ & $\Delta \ln \left(q_{j, l}\right)$ \\
& 4.143 & -1.644 & 0.172 & -0.070 & 3.161 & -1.617 & 0.180 & -0.081 \\
$\Sigma_{k} w_{k} \theta\left(l_{k}\right)$ & $(1.097)$ & $(1.031)$ & $(0.056)$ & $(0.055)$ & $(1.004)$ & $(0.858)$ & $(0.052)$ & $(0.045)$ \\
$R^{2}$ & -0.897 & 0.505 & -0.033 & 0.021 & -0.418 & 0.523 & -0.025 & 0.024 \\
$N$ & $(0.445)$ & $(0.393)$ & $(0.023)$ & $(0.021)$ & $(0.448)$ & $(0.344)$ & $(0.021)$ & $(0.016)$ \\
& 0.136 & 0.018 & 0.101 & 0.013 & 0.238 & 0.023 & 0.222 & 0.022 \\
& 435 & 435 & 435 & 435 & 435 & 435 & 435 & 435 \\
\hline
\end{tabular}

OLS estimates of price and quantity response regressions. The dependent variables are 100 times the change in the natural logarithm of contract price and 100 times the change in the natural logarithm of quantity. Losses are measured in billions of dollars. Exposure to each type of catastrophe loss $(w)$ is calculated directly by simulation. Each column corresponds to a separate regression. Four different assumptions are made about the functional form of distributed lag of losses that affects prices. In Columns 1 and 2, the loss variable is simply the sum of two lagged quarterly losses, in Columns 3 and 4 it is the sum of squared losses from two lagged quarters, in Columns 5 and 6 it is the sum of four lagged quarterly losses, and in Columns 7 and 8 it is the sum of squared losses from four lagged quarters.

Table 8: The response of price and quantity losses, exposure measured directly by catastrophe type

\begin{tabular}{|c|c|c|c|c|c|c|c|c|}
\hline & $\sum_{s=}^{2}$ & & $\sum_{s=}^{2}$ & & & & & $t-s-1$ \\
\hline \multirow{3}{*}{$\Sigma_{k} \theta\left(l_{k}\right)$} & $\Delta \ln \left(p_{j, l}\right)$ & $\Delta \ln \left(q_{j, t}\right)$ & $\Delta \ln \left(p_{j, t}\right)$ & $\Delta \ln \left(q_{j . t}\right)$ & $\Delta \ln \left(p_{j, t}\right)$ & $\Delta \ln \left(q_{j, t}\right)$ & $\Delta \ln \left(p_{j . t}\right)$ & $\Delta \ln \left(q_{j, t}\right)$ \\
\hline & 1.491 & -0.771 & 0.091 & -0.045 & 0.535 & 0.025 & -0.035 & -0 . \\
\hline & (1.137) & $(1.097)$ & $(0.055)$ & $(0.053)$ & $(1.126)$ & $(1.060)$ & $(0.089)$ & $(0.073)$ \\
\hline \multirow{2}{*}{$w_{E \underline{Q}}^{\theta\left(l_{E Q}\right)}$} & 65.826 & -30.015 & 44.099 & -17.720 & 24.265 & -35.153 & 26.740 & -29.059 \\
\hline & $(50.672)$ & $(17.103)$ & $(37.030)$ & $(10.130)$ & $(16.375)$ & $(16.931)$ & $(11.852)$ & $(12.808)$ \\
\hline \multirow{2}{*}{$w_{F I} \theta\left(l_{F I}\right)$} & -26.137 & -8.489 & 6.451 & -11.843 & -36.406 & 13.440 & -3.873 & -1.220 \\
\hline & $(28.439)$ & $(20.256)$ & (11.162) & $(6.311)$ & $(32.047)$ & $(21.315)$ & $(15.906)$ & $(7.531)$ \\
\hline \multirow{2}{*}{$w_{H R} \theta\left(l_{H R}\right)$} & -0.218 & 0.307 & -0.015 & 0.016 & 0.266 & 0.010 & 0.028 & 0.0 \\
\hline & $(0.446)$ & $(0.410)$ & $(0.022)$ & $(0.020)$ & $(0.459)$ & $(0.410)$ & $(0.031)$ & $(0.026)$ \\
\hline \multirow{2}{*}{$w_{W S} \theta\left(l_{W S}\right)$} & 51.084 & 13.796 & 27.597 & 12.133 & 21.862 & 10.452 & -5.706 & 10.512 \\
\hline & $(25.298)$ & $(9.816)$ & $(20.651)$ & $(8.235)$ & $(21.868)$ & $(12.211)$ & $(21.304)$ & $(14.074)$ \\
\hline \multirow{2}{*}{$w_{W D} \theta\left(l_{W D}\right)$} & 9.273 & -3.362 & 5.912 & -1.883 & 5.905 & -2.918 & 2.726 & -0.881 \\
\hline & (1.771) & $(1.200)$ & $(0.762)$ & $(0.399)$ & $(1.226)$ & $(1.088)$ & $(0.622)$ & $(0.415)$ \\
\hline$R^{2}$ & 0.249 & 0.038 & 0.264 & 0.032 & 0.301 & 0.056 & 0.291 & 0.039 \\
\hline$N$ & 435 & 435 & 435 & 435 & 435 & 435 & 435 & 435 \\
\hline \multicolumn{9}{|c|}{$\begin{array}{l}\text { OLS estimates of price and quantity response regressions. The dependent variables are } 100 \text { times the change in the natural } \\
\text { logarithm of contract price and } 100 \text { times the change in the natural logarithm of quantity. Losses are measured in billions of } \\
\text { dollars. Exposure to each type of catastrophe loss }(w) \text { is calculated by simulation. Each column corresponds to a separate } \\
\text { regression. Four different assumptions are made about the functional form of distributed lag of losses that affects prices. In } \\
\text { Columns } 1 \text { and } 2 \text {, the loss variable is simply the sum of two lagged quarterly losses, in Columns } 3 \text { and } 4 \text { it is the sum of squared } \\
\text { losses from two lagged quarters, in Columns } 5 \text { and } 6 \text { it is the sum of four lagged quarterly losses, and in Columns } 7 \text { and } 8 \text { it is } \\
\text { the sum of squared losses from four lagged quarters. EQ denotes earthquake, FI fire, HR hurricane WS winter storm and WD } \\
\text { windstorm. OLS standard errors in parentheses. }\end{array}$} \\
\hline
\end{tabular}


Table A1: Value of knockout provision in single-event excess-of-loss contracts

\begin{tabular}{|c|c|c|c|c|c|c|c|c|}
\hline \multirow{3}{*}{$\begin{array}{l}\text { Inception } \\
\text { date }\end{array}$} & (i) & (ii) & (iii) & (iv) & (v) & $(v i)$ & $(v i i)$ & (viii) \\
\hline & \multicolumn{8}{|c|}{ Panel (a) } \\
\hline & Quake & Fire & $\begin{array}{l}\text { Hurricane } \\
\text { (SE) }\end{array}$ & $\begin{array}{c}\text { Hurricane } \\
\text { (NE/TX) }\end{array}$ & $\begin{array}{l}\text { Winter } \\
\text { storm }\end{array}$ & $\begin{array}{l}\text { Wind } \\
\text { storm }\end{array}$ & Sum & All-type \\
\hline Jan. 1 & 1.9 & 2.7 & 6.5 & 7.8 & 1.7 & 9.8 & 30.4 & 22.3 \\
\hline \multirow[t]{3}{*}{ July 1} & 1.9 & 2.7 & 6.5 & 7.8 & 1.7 & 9.9 & 30.4 & 22.9 \\
\hline & \multicolumn{8}{|c|}{ Panel (b) } \\
\hline & $\mathrm{NE}$ & $\mathrm{SE}$ & TX & MW & $\mathrm{CA}$ & & Sum & $\begin{array}{l}\text { All- } \\
\text { region }\end{array}$ \\
\hline Jan. 1 & 6.1 & 8.9 & 7.8 & 3.7 & 3.9 & & 30.4 & 22.3 \\
\hline July 1 & 6.3 & 8.9 & 7.7 & 3.8 & 3.9 & & 30.5 & 22.9 \\
\hline
\end{tabular}

Expected reinsurance payments (in millions of dollars) for a $\$ 100$-million-excess-of- $\$ 500$-million contract under various contract payment provisions. In Panel (a), the contract is single-event, but payment is contingent on the type of catastrophe. Thus in column (i), the contract matures on the occurrence of the first earthquake event that produces $\$ 500$ million in insured losses. Column (vii) gives the sum of the expected payments from the contracts in Columns (i) to (vi). Column (viii) is the value of expected payments under an all-event contract that matures on the occurrence of any event producing $\$ 500$ million in insured losses. The difference between Column (vii) and Column (viii) is the value of the event knockout provision implicit in singleevent, all-event contracts. Panel (b) is structured in exactly the same fashion, except that it distinguishes events by region rather than type. The five regions are: Northeast, Southeast, Texas, Midwest and California. 